\title{
A crítica da razão governamental em Michel Foucault
}

\author{
MICHELSENELLART
}

RESUIMO: O artigo examina a crítica da razão governamental moderna efetuada por Foucault sob dois aspectos fundamentais: em primeiro lugar, analisa a noção de crítica a partir de uma certa leitura que faz de Kant, articulada a uma ontologia do presente. Em segundo lugar, investiga o lugar ocupado pelo liberalismo neste procedimento crítico. Procura enfim mostrar que a crítica de Foucault escapa à imputação de reformismo.

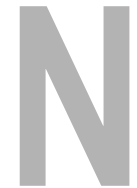

uma conferência pronunciada em 1979 nos Estados Unidos, Foucault explicava o que era, a seu ver, a tarefa da filosofia: efetuar uma "crítica da razão política”. “(...) depois de Kant, o papel da filosofia tornou-se o de impedir a razão de ultrapassar os limites daquilo que é dado na experiência; mas, a partir desta época, (...) o papel da filosofia tornou-se também o de vigiar os abusos de poder da racionalidade política (...)"(Foucault, 1994e, p. 181).

Ele opõe à ilusão, que é própria da razão, de dizer o que deve ser o poder, a função, aparentemente negativa, de um contrapoder permanente ${ }^{1}$. De que modo, contudo, ela poderia exercer este papel? Não apenas pela vigilância em relação às práticas efetivas do poder - tarefa que é de responsabilidade de todos os cidadãos - mas pela desmontagem de seus mecanismos e pela análise da racionalidade à qual obedecem. Esta racionalidade, nas sociedades ocidentais modernas, caracterizava-se por apresentar duas faces, uma individualizante e outra totalizante. Tinha sua origem na idéia cristã de um

UNITERMOS:

Foucault, razão governamental, a atitude crítica, poder, liberalismo.

Professor do Departamento de Filosofia da Universidade de Nancy 
SENELLART, Michel. A crítica da razão governamental em Michel Foucault. Tempo Social; Rev. Sociol. USP, S. Paulo, 7(1-2): 1-14, outubro de 1995.

${ }^{1}$ Sobre a filosofia como contrapoder, e as diferentes figuras do filósofo como antidéspota (o filósofo legislador, o conselheiro do príncipe, ou o cínico que ri do poder) aos quais Foucault acrescenta o esboço de uma outra atitude possível (Foucault, 1994c, p.537, 539-540).

2 A palavra, que não é empregada em Omnes et singulatim, (Foucault, 1994c) aparece pela primeira vez na quarta lição do curso de 1978 do Collège de France: Segurança, território, população (Foucault, 1994b, p. 635-657 esp. p. 655).

3 Para uma "crítica racional da racionalidade"'(cf. Foucault, 1994h, p. 440). Foucault assinala sua diferença em relação aos teóricos da Escola de Frankfurt, recusando a idéia de uma racionalidade e de uma bifurcação únicas: “(...) eu, por mim, não falaria de uma bifurcação da razão, mas antes de uma bifurcação múltipla, incessante, uma espécie de ramificação copiosa. Não falo do momento em que a razão se tornou tecni-cista (...)".

4 Cf. em paricular Dreyfus e Rabinow (1984, p. 313), cf. também meu artigo (1993, p. 287-288). poder pastoral encarregado dos indivíduos, para conduzí-los, com paciência e firmeza, em direção à salvação, e na idéia de razão de Estado, que aparece no século XVI, como princípio de fortalecimento do poder estatal. Estas duas tendências vinham se articular, no século XVIII, na teoria do Estado de polícia, ou seja, de um Estado que tende a aumentar o seu poder, cuidando, de uma maneira minuciosa e metódica, da felicidade de seus súditos (de onde o nome de Estado de bem-estar, Wohfahrtsstaat, pelo qual é também designado). A implantação de técnicas pastorais no quadro do aparelho de Estado: tal era, para Foucault, a matriz da razão política moderna. Propunha então chamar com a estranha palavra "governabilidade" o processo que tinha conduzido da pastoral cristã ao Estado de polícia e que se prolongava até nós ${ }^{2}$. O "governo" não era a simples instrumentalização da força de um Estado cada vez mais compacto, mas uma figura original do poder, articulando técnicas específicas de saber, de controle e de coerção. Uma certa racionalização, pois, historicamente definida, das relações de poder

É por isso que a crítica da razão política não consistia em fazer o processo da razão, como se ela fosse portadora, em sua lógica tecnicista, de um devir totalitário (cf. Foucault, 1994e, p. 135-136) ${ }^{3}$, mas em mostrar que efeitos haviam sido produzidos pela racionalidade estabelecida, no Ocidente, no início dos Tempos modernos. Esta análise tomava a direção diametralmente oposta a três tipos de discurso: o discurso revolucionário, o discurso individualista liberal, o discurso libertário. Foucault censurava o primeiro, que reduz o poder a uma violência de classe, e lhe opõe uma estratégia geral de conquista, não somente por simplificar em demasia o campo múltiplo, instável, heterogêneo, dos conflitos que atravessam a sociedade, mas também por confundir poder e violência ${ }^{4}$. Ao segundo, que define o indivíduo, seus interesses e seus direitos, como puro limite da ação do Estado, ele objetava que o indivíduo faz parte da mesma história deste último. O indivíduo não é anterior ao Estado. Ele é o produto das técnicas individualizantes do "governo". Ao terceiro, enfim, que rejeita a política em nome de uma espontaneidade sem entraves ou de uma alteridade radical, Foucault respondia que não há exterioridade em relação ao poder. Sempre se está preso em suas “malhas” (cf. Foucault, 1994d, p. 182-194), implicado em seu jogo, o que não significa ser seu prisioneiro. É inútil opor à razão política, uma maneira de pensar não política. O importante é inventar novas condutas contra a dominação insidiosa da governabilidade estatal. A problemática do "governo", pela qual Foucault rompia com certos aspectos de seu próprio engajamento dos anos 70 (cf. Senellart, 1993, p. 284-288), tem assim seu corolário na ética do cuidado de si, que é uma ética política, desenvolvida pelos seus últimos livros.

Tal era, em suas grandes linhas, o programa apresentado por Foucault, de uma crítica da razão governamental.

Esta noção de "crítica", todavia, levanta diversas questões. Podese perguntar em primeiro lugar - questão abrupta, sem dúvida, mas freqüentemente colocada - se ela traduz a passagem do extremismo revolucionário, do 
qual seus escritos e seus atos após 1968 dão testemunho, a um reformismo moderado. A crítica seria a forma apaziguada da luta quando a revolução deixa de ser desejável? Pode-se perguntar, além disso, de que ponto de vista esta crítica pode ser efetuada, já que Foucault nega toda exterioridade em relação ao poder. Como combater o que nos envolve, se não podemos nos desvencilhar dele a partir da referência a uma natureza primeira, a uma essência fundadora ou a uma consciência universal? Pode-se perguntar, enfim, que relações a crítica proposta por Foucault mantém, não somente com o pensamento de Kant, ao qual ele retorna com insistência, mas com sua própria análise do liberalismo como "reflexão crítica sobre a prática governamental" (cf. Foucault, 1989, p. 116 - curso de 1979). Estas questões, aparentemente distintas, de fato são solidárias umas com as outras. Organizam-se em torno da busca de uma atitude que associa, num mesmo movimento, a resistência ao poder, a constituição de si e o diagnóstico do presente.

Já que me deram a honra de pedir que fizesse a abertura destas jornadas de trabalho sobre a atualidade de Foucault, onze anos depois de sua morte, pareceu-me útil me perguntar sobre o sentido desta "atitude crítica", à qual ele consagrou sua última reflexão, a partir de uma investigação, que não pôde levar a termo, sobre a razão governamental. A questão da crítica será então objeto de minha exposição. Mas ela constitui igualmente a abertura a partir da qual se pode travar um diálogo exigente e fecundo com a obra de Foucault. Esta se encerra, não com um gesto que a fecha sobre si mesma, mas com a recusa de se abandonar a seu próprio comentário. Ao acaso da morte, que veio interrompêla subitamente, corresponde, mais essencialmente, o esforço de "se desprenderse de si mesma" (cf. Foucault, 1984, p.14), que, de nossa parte, nos convida à reflexão crítica.

Examinarei, pois, num primeiro momento, a maneira pela qual Foucault define a noção de crítica a partir de uma certa leitura de Kant, articulada ao projeto de uma "ontologia do presente". Ver-se-á assim que a crítica se define como uma atitude, um ethos, uma maneira de agir, inseparável do diagnóstico de uma crise. Examinarei em seguida o lugar singular que o liberalismo ocupa neste procedimento crítico: de que modo se inscreve no seio da racionalidade governamental moderna ao mesmo tempo em que a contesta e como Foucault se situa em relação ao mesmo liberalismo. Tentarei mostrar que esta problemática escapa à imputação de reformismo, sem cair por isto no impasse da negação radical. Em parte, apoiar-me-ei sobre materiais não retomados em Dits et écrits, e mesmo em materiais inteiramente inéditos, como os cursos ministrados no Collège de France em 1978 e 1979. São territórios do pensamento foucaultianos que precisam a ser explorados.

Sabe-se que Foucault manteve um longo diálogo com o pensamento de Kant. Minha intenção aqui não é a de reconstituir as etapas deste diálogos ${ }^{5}$. Lembrarei simplesmente que, em As palavras e as coisas, publicado em
5 Para uma análise aprofundada, numa perspectiva interpretativa que exigiria aliás uma discussão, cf. Béatrice Han (1995). 
${ }^{6}$ Cf. em especial Foucault (1966, cap IX, p. 323 ss.), Dreyfus e Rabinow (1984, p. 47-50) e Habermas (1988, p. 308-311).

7 Foucault (artigo assinado por Maurice Florence (1984, p. 631). O texto começa por uma frase, colocada entre parênteses, de F. Ewald, ratificada por Foucault: "Se Foucault se inscreve em alguma tradição filosófica, é na tradição crítica de Kant (...)".

8 Ver também Foucault (1994f), e com o mesmo título, (1994g) (este último texto, extraído de um curso de 1983, é de fato anterior ao precedente).

${ }^{9}$ A respeito desta distinção entre atitude e doutrina, cf. Foucault (1994f, p. 571).

${ }^{10}$ Que Foucault traduz por "tenha a coragem, a audácia de saber" (1994f, p. 565).
1966, Kant aparece como um filósofo que, pela sua "analítica da finitude", abriu o campo do saber antropológico. Com o fim da metafísica, cabe ao homem, consciente de seus limites, fundar suas certezas últimas. Tarefa infinita, que, paradoxalmente, procede de sua própria finitude, e em cuja realização ele se torna sujeito e objeto de seu próprio conhecimento. Assim se abre a era da modernidade, na qual o homem, desligado de toda garantia transcendente, se oferece ao império de sua vontade desenfreada de verdade. As ciências humanas nasceram nesta virada decisiva ${ }^{6}$. O Kant de As palavras e as coisas, para dizê-lo sumariamente, assinala pois o advento, na cultura ocidental, de um saber que se exerce sobre o homem que fala, vive e trabalha. Saber ao qual ele opõe então as "contraciências" da etnologia, da psicanálise e da lingüística, que descobrem, no homem, a existência de estruturas constituintes. É este mesmo saber que Foucault, em Vigiar e punir (1975, p. 227), associa (mas apagando agora toda referência a Kant) à formação das técnicas disciplinares.

Ora, Foucault, em 1980, inscrevendo-se explicitamente na tradição kantiana, afirma que quis fazer, através de seus diferentes livros, uma "história crítica do pensamento" ". Mais do que isso, em 1983 e 1984, consagra vários textos ao opúsculo de Kant $O$ que é a Ilustração? (1784), no qual vê aparecer, pela primeira vez, a definição de uma "forma de filosofia" que problematiza a atualidade da qual faz parte e que ele mesmo tentou praticar (cf. Foucault, 1994g, p. 688) ${ }^{8}$. Como explicar esta aparente reviravolta? Dever-se-ia ver, como o faz Habermas, uma "contradição gritante" entre a denúncia implacável dos efeitos do poder produzidos pela moderna vontade de verdade e a retomada desta vontade sob a forma de uma impulsão crítica libertadora? (Habermas, 1986, p. 799). Foucault previne esta objeção distinguindo em Kant a origem de "duas grandes tradições críticas": uma, que "coloca a questão das condições sob as quais um conhecimento verdadeiro é possível" e a partir da qual "toda uma face da filosofia moderna (...) se desenvolveu como analítica da verdade", e outra, que se delineia na questão da Aufklärung, e que se interroga sobre a significação do presente e traça a via de uma "ontologia de nós mesmos" (cf. Foucault, 1994g, p. 687). De um lado, pois, a Crítica da razão pura, do outro, o artigo O que é a Ilustração?, definindo dois modos distintos de interrogação crítica. É a distância, a tensão entre estes dois tipos de questionamento que permite a Foucault reativar a "atitude" kantiana, sem aderir à doutrina de Kant ${ }^{9}$. Sem dúvida, esta leitura de Kant mereceria uma discussão, que não posso fazer aqui. Deter-me-ei apenas em três pontos da interpretação proposta por Foucault:

a) Através da maneira pela qual Kant coloca a questão da Aufklärung - esta, lembremo-nos, é a saída do homem do estado de minoridade, ou de dependência infantil, da qual o próprio homem é responsável, e tem por divisa Aude sapere, "tenha a coragem de pensar por si mesmo" 10 -, ele descobre o esboço de uma "atitude" totalmente nova. Por "atitude", entende um certo "modo de relação com a atualidade" (Foucault, 1994f, p. 568), que não é o do espectador, mas o de um sujeito ator do presente do qual ele faz parte 
SENELLART, Michel. A crítica da razão governamental em Michel Foucault. Tempo Social; Rev. Sociol. USP, S. Paulo, 7(1-2): 1-14, outubro de 1995.

(Foucault, 1994g, p. 680). Segundo Foucault, Kant é o primeiro filósofo que problematiza sua atualidade, para definir nela o modo de ação do seu discurso. A atitude crítica é portanto indissociável de uma "ontologia do presente" (Foucault, 1994g, p. 687): o que, no presente, tem sentido para aquele que fala dele? O que o constitui, não como momento fugaz, mas como acontecimento que deve ser pensado?

b) Este acontecimento, segundo Kant, não é somente o da Aufklärung, mas igualmente o da Revolução. Foucault vê em $O$ conflito das faculdades, escrito por Kant em 1798, a continuação do artigo de 1784. Nele Kant coloca a seguinte questão: "Há um progresso constante para o gênero humano?" "1. Não basta, diz ele, mostrar que existe uma causa possível deste progresso (a liberdade do homem como ser moral), deve-se ainda "procurar um acontecimento" que dê testemunho da ação desta causa. Já que este acontecimento tem um valor de sinal, Kant o encontra, não na violência revolucionária, mas no "entusiasmo" que a experiência da Revolução suscita em seus espectadores. O entusiasmo pela Revolução é o sinal de uma disposição moral da humanidade que aspira a dar a si mesma uma constituição republicana. A Revolução realiza assim o processo da Aufklärung. É por isso que a atitude crítica consiste em pensar conjuntamente estes dois acontecimentos solidários. O que é este momento da história da razão que significa a Aufklärung? O que fazer com o entusiasmo pela Revolução? Questões que ainda são as nossas no final do século XX.

c) A referência ao modelo kantiano não constitui, para Foucault, um retorno a Kant, mas um esforço para desvencilhar a atitude crítica dos limites nos quais, desde o próprio Kant, a questão crítica a havia encerrado. Esta, com efeito, assinala para ele um recuo em relação à análise da Aufklärung. Em Kant, em primeiro lugar, que não levou às últimas conseqüências a sua própria máxima crítica (“Tenha a coragem de pensar por si mesmo"). Ao deslocar a crítica para o plano das condições do saber, ele neutralizou os seus efeitos políticos. Ao invés de opor a autonomia à obediência ao soberano, por uma reviravolta não menos paradoxal do que aquela descrita em As palavras e as coisas, Kant fundou esta obediência na própria autonomia ${ }^{12}$. Na história dos séculos XIX e XX, em seguida, que "deu mais ensejo à continuação do empreendimento crítico kantiano tal como ele o havia situado de certa forma como recuo em relação à Aufklärung, do que a alguma coisa como a própria Aufklärung" (Foucault, 1990, p. 41).

Foucault vê aí três exemplos, entre os quais "se constrói todo um tecido de estreitas relações" no desenvolvimento de uma ciência positivista, do poder estatal, e, na costura das duas, de uma ciência do Estado (1990, p. 42). Como reação, a questão da Aufklärung, desde a esquerda hegeliana até a Escola de Frankfurt, tomou a forma de uma desconfiança crescente em relação à racionalização e a suas recaídas dominadoras. É nesta linhagem que Foucault se situa. A atitude crítica consiste pois em repensar a Aufklärung, não como a aurora do reino luminoso da razão, mas como esforço permanente
${ }^{11}$ Esta questão é o objeto da segunda seção da obra, relativa ao conflito da faculdade de filosofia com a faculdade de direito

${ }^{12}$ Cf. Foucault (1990, p. 41) (estranhamente, este texto não é retomado em Dits et écrits): “(...) em relação à Aufklärung, a crítica será, para Kant, o que ele vai dizer ao saber: sabes até onde podes saber? Raciocina quanto quiseres, mas sabes bem até onde podes raciocinar sem perigo? A crítica dirá, em suma, que nossa liberdade está menos naquilo que empreendemos, com maior ou menor coragem, do que na idéia que fazemos de nosso conhecimento e de seus limites, e que, conseqüentemente, em lugar de deixar outro dizer: "obedecei", é neste momento, quando se tiver uma idéia justa de seu próprio conhecimento, que se poderá descobrir o princípio da autonomia e não se estará mais obrigado de ouvir o obedecei; ou antes, que o "obedecei" estará fundado sobre a própria autonomia". 
para interrogar as racionalidades, tagarelas ou mudas, que nos conduzem. Conseqüentemente, ela implica que se inverta o procedimento kantiano, passando de uma crítica em termos transcendentais a uma crítica em termos de práticas imanentes. Kant perguntava quais eram as condições formais de todo conhecimento possível. Doravante é preciso analisar os mecanismos que, numa sociedade, produzem o saber real, com os efeitos de poder que dele resultam.

O que é o presente ao qual pertenço? Que acontecimento - por exemplo, o da Revolução e seu desaparecimento - me obriga a pensar? De que modo eu mesmo estou comprometido por esta pertinência, e através de que vias poderia transformá-la? Para Foucault, tais são as questões que definem a atitude crítica. Compreende-se então por que ela não requer nenhuma transcendência do sujeito. Não é a partir de um ponto de vista universal, o da natureza, de uma pura consciência, ou de um fim da história que se opera a crítica de um estado de coisas, mas a partir do próprio interior da racionalidade que o governa, em seus pontos de tensão ou de fragilidade. A crítica, em outros termos, não pressupõe a existência de um sujeito plenamente consciente de si. Ela não é da ordem de um juízo que sobrevoa a realidade histórica do alto de uma posição ideal de verdade. Procede das crises que atravessam a espessura de uma racionalidade, em suas múltiplas dobras. É por isso que ela não pode, do mesmo modo, pretender romper inteiramente com a racionalidade. A atitude crítica, escreve Foucault, não é "um comportamento de rejeição. Deve-se escapar à alternativa entre estar dentro ou estar fora; é preciso se situar nas fronteiras" (cf. Foucault, 1994f, p. 574). Nova reviravolta da questão kantiana: esta última se exercia "na forma da limitação necessária", enquanto se trata de experimentar, através de uma crítica prática, "as formas da ultrapassagem possível"(p. 574).

É nesta juntura da reflexão foucaultiana que se vê a articulação entre a questão crítica, tal como ele a reformula, e a problemática do governo. Tanto uma quanto outra, com efeito, são introduzidas por um mesmo movimento, numa conferência de 1978, o ano em que Foucault reelabora sua análise do poder a partir do conceito de "governabilidade". Infelizmente, esta conferência, publicada tardiamente em $1990^{13}$, não foi retomada em Dits et écrits. Portanto, a despeito de sua importância, ela é dificilmente acessível. Foucault a havia intitulado provisoriamente Qu'est-ce que la critique?, por não ousar, como confessa, chamá-la de Qu'est-ce que l'Aufklärung ? $^{14}$. Ela constitui a primeira versão dos textos que mais tarde assumirão plenamente este título. Mas cobre igualmente uma área muito diferente, porque, de um lado, restitui o tema crítico na história da filosofia contemporânea e, mais precisamente, em relação às etapas anteriores (arqueologia, genealogia) do trabalho de Foucault, e de outro lado, porque põe em evidência o estreito laço que une a atitude crítica ao surgimento da governabilidade. Detenhamo-nos

${ }^{13}$ Cf. supra nota 12 .

${ }^{14}$ Sobre esta questão do título cf. Foucault (1990, p. 36, 53). no primeiro exemplo apresentado por Foucault. Ele mostra claramente de que modo a crítica, longe de transcender o presente, se inscreve nas dobras dos jogos de poder. 
O cristianismo havia desenvolvido, nos primeiros séculos, uma nova concepção do governo como arte de dirigir as almas. Esta pedagogia pastoral estava no centro das atividades da Igreja, mas só se exerceu, durante muito tempo, em espaços bastante restritos (monastérios, comunidades espirituais). Ora, nos séculos XV e XVI produziu-se "uma verdadeira explosão da arte de governar", sob a forma, de início, de uma laicização, depois de um reforço distribuído em todos os planos, no espiritual, sem dúvida, mas também no familiar, doméstico, social, político, militar. Uma das questões fundamentais desta época inquieta, na saída do feudalismo, foi “como governar?” Governabilização das relações entre os homens que Foucault designa, em outro texto, como "uma crise geral do pastorado"(cf. 1989, p. 100 - curso de 1978). Contudo, este fenômeno não pode ser dissociado de uma outra questão: “como não ser governado?”, ou, pelo menos, The Criticism of Governamental Reason in Michel Foucault "como não o ser de uma tal maneira, por tais pessoas, para tal ou tal fim?" É deste lado, diz Foucault, do lado de uma certa desconfiança, reticência, resistência ao governo, mas também de um desejo de governar de outro modo, que se situa a atitude crítica. Ele assinala seus principais pontos de ancoragem, no retorno à Escritura contra o magistério eclesiástico, na invocação de um direito natural contra a onipotência do soberano, no raciocínio científico contra o peso da autoridade. É certo que essas críticas fazem prevalecer um universal (A Bíblia, o direito, a ciência) contra um sistema de dominação particular, mas o fazem no interior de um dispositivo que liga estreitamente poder e verdade: se o poder reinvidica uma verdade, é preciso por sua vez combatê-lo pela verdade. A crítica pode então ser entendida como "uma arte da não servidão voluntária”, muito próxima, segundo Foucault, da maneira pela qual Kant define a Aufklärung ${ }^{15}$.

Este exemplo não explica simplesmente a gênese da atitude crítica, na cultura ocidental, como uma resposta à governabilização da sociedade. Ele ajuda a compreender a maneira segundo a qual Foucault, no ano seguinte, aborda a questão do liberalismo. É esta última que gostaria de examinar agora. Se toda crítica, como se viu, procede de uma crise, a qual delas corresponde a crítica liberal da política? E que relações a atitude crítica mantém com ela? São homogêneas uma em relação a outra, de modo que ser crítico, doravante, significa ser liberal? Não é esta a conclusão de Foucault. Mas sua resposta passa por um longo desvio, que é preciso reconstituir esquematicamente.

\section{II}

Foucault analisa o liberalismo, não como teoria econômica ou jurídica, mas como uma certa prática refletida de governo. Ele o opõe ao modelo do Estado de polícia, que dominava, até o século XVIII, a maior parte das monarquias européias. Em si mesma, esta oposição não tem nada de original. Ela já aparece nos liberais alemães, que, seguindo a mesma trilha de Kant ${ }^{16}$, haviam denunciado o despotismo do Estado de polícia, em nome dos princípios do Estado de direito. É o argumento central, por exemplo, do famoso Essai
${ }^{15}$ Sobre todo este desenvolvimento, cf. Foucault (1990, p. 37-39).

16 Sobre a crítica de Kant ao Estado patriarcal do bem-estar, cf. Théorie et pratique (1793, p. 31), "um governo que fosse fundado sobre o princípio da benevolência em relação aos povos, tal com o do pai em relação aos filhos, (...) no qual, conseqüientemente, os súditos (...) são obrigados a se comportar de maneira unicamente passiva, a fim de esperar somente do chefe do Estado a maneira pela qual devem ser felizes (...) - um tal governo, digo, é o maior despotismo que se possa conceber"; denunciando a confusão entre o "princípio da felicidade" e o "princípio do direito", ele escreve que "o soberano que quer tornar o povo feliz segundo a idéia que ele tem de felicidade e (...) se torna déspota”(p. 44-45). 
17 Ideen zu einem Versuch, die Grenzen der Wirsamkeit des Staates zu bestmmen. Este livro só foi publicado em 1851, depois da morte de seu autor. Eu o cito na tradução de H. Chrétien, Paris, 1867. Boa síntese da obra em P. Rosanvallon (1984, p. 74-77). sur les limites de l'État, escrito por Guillaume de Humboldt em $1792^{17}$. Este distingue dois objetos possíveis para o cuidado do Estado: o bem positivo, que consiste no bem-estar físico dos súditos, e o bem negativo, que consiste em sua segurança. $\mathrm{O}$ Estado que busca o primeiro tende a ampliar indefinidamente seu domínio, a transformar os homens em máquinas e a uniformizar a sociedade. Só a busca do bem negativo, conseqüentemente, é compatível com as exigências da liberdade. Segurança contra bem positivo: a fórmula retomada, no século XIX, por todos os partidários de um Estado mínimo. Foucault, contudo, não se contenta em lhes fazer eco. Opõe as duas lógicas não em termos de direito, mas de racionalização. Enquanto, segundo o princípio da polícia (em outras palavras, do Estado de bem-estar), "nunca se governa demais", pois muitas coisas escapam ao controle administrativo, o liberalismo, por sua vez, é atravessado pela suspeita de que "sempre se governa demais" (Foucault, 1990, p. 111). A racionalização liberal do governo obedece a uma regra de economia máxima. Não no sentido que se queira governar o mais possível com o menor custo, mas no sentido em que se pergunta se não é mais custoso governar do que não governar. Será verdadeiramente necessário governar? Como se sabe, esta era a questão colocada por Thomas Paine em 1792. Transpondo as idéias de Adam Smith para o terreno político, ele afirmava que a sociedade não teve necessidade do governo para se desenvolver.

"Uma grande parte desta ordem que reina entre os homens não é efeito do governo. Ela tem sua origem nos princípios da sociedade e da constituição natural do homem. Existia antes do governo, e continuaria a existir se a formalidade do governo fosse abolida. (...) [Pelo jogo de interesse recíproco] a sociedade realiza por si mesma tudo o que é atribuído ao governo" (Paine, 1792, p. 11).

Disto ele extrai a conseqüência de que a sociedade, pelos mecanismos naturais da troca e da divisão do trabalho, ao assegurar a ordem e a prosperidade melhor do que poderia fazer o melhor governo, torna-o desnecessário. Apenas as fraquezas humanas justificam a conservação de um mínimo de Estado. A idéia de uma sociedade imediata a si mesma, auto-regulando-se pelo jogo de interesses, funda assim uma crítica radical do governo. É ela, escreve Foucault,

"que permite desenvolver uma tecnologia de governo a partir do princípio de que ele é, em si mesmo, 'a mais' (...), que ele vem se acrescentar como um suplemento ao qual se (...) deve sempre perguntar se é necessário e para que é útil"' (1990, p. 112-113).

Como governar, contudo, se se governa sempre demais? Tal é, para Foucault, a questão que faz do liberalismo uma prática de governo original, ligada, em seu funcionamento, à crítica permanente de si mesma. É por esta razão que ele vê nela "uma forma de reflexão crítica sobre a prática governamental” (Foucault, 1990, p. 116). Crítica não somente das práticas despóticas do Estado absoluto, mas da própria racionalidade do governo, como princípio que estrutura a sociedade. Crítica, pois, da razão governamental. Em que sen- 
tido esta crítica está ligada à atitude crítica problematizada por Foucault? É notável que, num de seus cursos sobre Adam Smith, ele aproxime a crítica liberal da crítica kantiana. Observemos mais de perto seus argumentos, a fim de melhor delimitar os contornos desta questão crítica.

O que é a "mão invisível” da qual fala Adam Smith, numa passagem célebre da Riqueza das nações? (1776, p. 43) Ela constitui um resquício teológico? Designa, no seio do mundo econômico, o lugar secretamente ocupado por um Deus providencial? Foucault recusa esta interpretação, pois o importante, na sua opinião, não é tanto a mão, substituto de uma providência que junta os fios dispersos dos interesses, mas sua invisibilidade, indispensável para a lógica do mercado. Ela implica que nenhum agente econômico deva visar ao bem geral, já que este é melhor servido, através da harmonização natural dos interesses, quando cada um trabalha por seu ganho pessoal. Nenhum agente econômico, mas também nenhum agente político.

"É impossível que o soberano possa ter um ponto de vista sobre o processo econômico que totalize cada um dos elementos e permita combinálos artificialmente ou voluntariamente" (Foucault, 1979, 11 1 lição).

Incapaz de adquirir um ponto de vista totalizante, o soberano deve ser cego. É a própria incognoscibilidade do processo econômico em seu conjunto que torna possível a composição dos interesses. Daí um novo tipo de limitação do poder estatal, não pelo recurso a direitos que não podem ser transgredidos, mas pela realidade de sua própria impotência. Ele não deve querer controlar a indústria dos particulares, porque não pode saber como ela concorre mais eficazmente para o interesse geral. Desqualificação da soberania, a partir da constituição da economia como espaço intotalizável:

"O liberalismo em sua consistência moderna começou quando (...) foi formulada esta incompatibilidade essencial entre (...) a multiplicidade não totalizável, característica dos sujeitos econômicos, e (...) a unidade totalizante

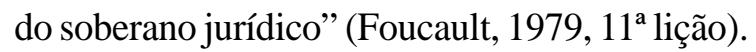

Este é, propriamente, o lugar crítico do liberalismo, no sentido kantiano do termo. Do mesmo modo que o homem não pode conhecer a totalidade do mundo, assim também o soberano não pode conhecer a totalidade do processo econômico. A crítica formal do conhecimento inaugura a era da finitude antropológica, a crítica econômica, a era da limitação governamental. Lembremo-nos, todavia, que a atitude crítica, para Foucault, não se identifica com a crítica kantiana, mas com aquilo que ele chama Aufklärung. Qual é pois a tarefa da Aufklärung em relação à crítica liberal da razão governamental? É tripla: tarefa de autocrítica, em seguida de contracrítica, enfim de radicalização crítica.

a) Em primeiro lugar, autocrítica. Sabe-se que lugar ocupava, em $\mathrm{Vi}$ giar e punir (1975), o panóptico de Bentham, esta utopia arquitetural concebida, no fim do século XVIII, para racionalizar a administração das prisões: idealtipo do estado de polícia, "fazendo funcionar o projeto de uma visibilidade universal (...), em proveito de um poder rigoroso e meticuloso" (Bentham, 1977, p. 16) ${ }^{18}$.
${ }^{18}$ Ver também Foucault, (1994, p. 195) e (1975, p. 201-206). 
Diferentemente da soberania, que se manifestava com ostentação, este poder se exercia de maneira invisível, impondo àqueles que submetia uma visibilidade obrigatória. Forma pura de tecnologia disciplinar, a prisão benthamiana levava à perfeição um dispositivo de controle estabelecido desde a idade clássica, e do qual as próprias ciências humanas tiravam sua existência. É por isto que Foucault, em 1975, podia caracterizar a modernidade como a era da sociedade disciplinar.

Ora, se o panóptico oferecia o modelo de um poder tanto mais eficaz quanto mais era engenhoso, a economia política liberal põe em cena uma representação absolutamente contrária: não mais um poder que tudo vê e tende a crescer indefinidamente, mas um poder cego, obrigado a autolimitar-se por sua invencível ignorância. Foucault é assim conduzido a rever seu diagnóstico do presente, fazendo aparecer, na idéia da "mão invisível" o princípio radical do panóptico. Bentham, num acesso de entusiasmo, havia comparado o poder do vigilante à onipotência divina. $\mathrm{O}$ dispositivo disciplinar se inscreve pois ainda, pelo seu projeto totalizante, numa visão teológica da sociedade. Inversamente, não há lugar para Deus no processo econômico. A economia, enquanto mostra a impossibilidade de um ponto de vista global sobre o Estado, representa a primeira teoria atéia do funcionamento social. Ela abre igualmente um outro espaço de resistência ao poder que não é aquele definido pelas técnicas disciplinares. Contra as disciplinas, não havia luta possível a não ser em termos de guerra (era a via revolucionária). A obscuridade do mercado, a opacidade da sociedade a qualquer olhar inquisidor permitem que múltiplas práticas de autonomia se manifestem.

b) Contracrítica, em seguida. Não se deveria acreditar, bem entendido, que o mercado seja o lugar de uma liberdade imediata e plena que poderíamos fazer valer contra todo excesso do governo. E isto pelo menos por três razões. A primeira, é que o liberalismo, como forma de pensamento crítico, constitui igualmente o eixo de uma governabilidade positiva que, segundo os contextos históricos ou nacionais, pode se transformar no seu contrário. Assim, a economia induziu as políticas antiliberais (Nationalökonomie do século XIX, economias planificadoras do século 20), do mesmo modo que o Estado de direito se revelou compatível com os regimes autoritários (cf. Foucault, 1989, p. 116). A segunda razão reside no fato de que se o liberalismo funciona pela liberdade (liberdade do mercado, do direito de propriedade, da discussão, da circulação, etc.), assim como o Estado de polícia funciona pela docilidade, esta liberdade deve tanto ser produzida por uma ação permanente do governo quanto protegida das usurpações que a ameaçam.

“(...) se o liberalismo não for tanto o imperativo da liberdade quanto a gestão (...) das condições sob as quais se pode ser livre, (...) será instaurada no coração mesmo desta prática liberal uma relação problemática, (...) sempre desigual, entre a produção da liberdade e aqueles mesmos que, ao produzíla, ameaçam limitá-la e destruí-la. (...) [ A produção da liberdade] implica (...) que se estabeleçam limitações, controles, coerções, obrigações apoiadas so- 
SENELLART, Michel. A crítica da razão governamental em Michel Foucault. Tempo Social; Rev. Sociol. USP, S. Paulo, 7(1-2): 1-14, outubro de 1995.

bre ameaças, etc. (...) Temos aí uma espécie de respiradouro para uma espantosa legislação, para uma espantosa quantidade de intervenções governamentais que serão a garantia da produção das liberdades das quais precisamente se tem necessidade para governar"(Foucault, 1979, 3ª lição).

É o cálculo do custo de fabricação desta liberdade que constitui o problema da segurança. A economia não é pois o domínio de uma pura espontaneidade individual, mas de uma liberdade solicitada, controlada, fabricada, cuja medida depende da relação, ela mesma variável, entre governantes e governados.

A terceira razão, correlativa às duas precedentes, se liga ao fato de que a racionalidade liberal não faz tábula rasa dos mecanismos reguladores forjados pelo governo do Estado de polícia. Ao contrário, ela se inscreve no interior de um movimento histórico que a obriga a assumir sua herança: a da formação do biopoder moderno. Em outras palavras, este poder, que se encarrega, não mais dos indivíduos, a fim de domá-los e sujeitá-los por intermédio de técnicas disciplinares, mas da população, a fim de regular seus processos biológicos (natalidade, mortalidade, longevidade, etc.). Foucault descreve a sua emergência, no século XVIII, no discurso dos teóricos do policiamento. Fenômeno capital a seu ver, que constitui uma das mutações mais importantes na história das sociedades humanas (cf. Foucault, 1994d, p. 194). Analisando a definição de "polícia" dada pelo cameralista alemão von Justi ${ }^{19}$, como ciência que não tem outro fim a não ser cuidar da felicidade de todos em vista de aumentar o poder do Estado ${ }^{20}$, Foucault mostra como, no século XVIII, o sistema de equilíbrio europeu obrigou os Estados a dar a si mesmos objetivos limitados em sua política externa e a buscar em sua política interna um objetivo ilimitado, a fim de se manter num estado de equilíbrio concorrencial com os outros Estados, através da maximização de suas forças.

Autolimitação externa, maximização interna de poder: esta estrutura, historicamente determinada, tem como resultado o aparecimento de um novo objeto de poder: a população como conjunto quantificável, massa viva suscetível a desvios e crises, fonte de riqueza, força de trabalho, reserva de guerra. Já que se trata de gerir a felicidade dos homens, por meio de medidas tão exatas quanto possível, em vista de reforçar o poder geral do Estado, é necessário conhecer e controlar as necessidades, os movimentos da população, as variáveis que a afetam. Daí o desenvolvimento paralelo da estatística, ciência da enumeração das coisas relativas ao Estado, e da economia, ciência da produção das riquezas. Um dos aspectos essenciais da "polícia" é pois a introdução da economia no governo político. É através desta mediação econômica que se associam, sem se confundir, a teoria da polícia e a arte liberal de governar.

c) Radicalização crítica, enfim - e terminarei com este último ponto. O liberalismo não é tanto uma solução quanto o indício de uma crise, ou de um limite crítico, no seio da governabilidade. Por isso, que é preciso se esforçar incessantemente para superar este limite. Foucault opõe à moderação do
${ }^{19}$ (1720-1771). A respeito deste autor, considerado como o principal pensador sistemático do cameralismo alemão do século XVII, cf. em particular, Pierangelo Schiera (1968, p. 434441); e Horst Dreitzel, (1987, p. 158-177).

${ }^{20}$ Justi (1756, prefácio): o autor distingue a "política", que "tem como finalidade a segurança pública tanto interna como externamente", da "polícia" que "tem por fim assegurar a felicidade do Estado pela sabedoria de seus regulamentos, e aumentar suas forças o quanto for capaz". Em seguida, ele explica que a palavra é tomada em dois sentidos diferentes, um, extenso - a "polícia" designando "as leis e regulamentos que concernem o interior do Estado" e o outro, limitado: neste caso a palavra indica tudo o que pode contribuir para a felicidade dos cidadãos, e principalmente para a manutenção da ordem e da disciplina, [assim como] os regulamentos que tendem a tornar cômoda a sua vida". "A polícia, ele conclui, deve se propor como regra fundamental fazer com que tudo o que compõe o Estado sirva para o fortalecimento e o crescimento de seu poder, assim como para a felicidade pública" (introdução, parág. 2-3,8). 
intelectual liberal a necessidade de uma "crítica radical" (Foucault, 1994a, p. 180). O papel do intelectual, diz ele, não é o de propor reformas, mas de contribuir, com seu trabalho, para a transformação da sociedade. Não é o de mudar as coisas, mas de mudar as maneiras de pensar que impedem que se conceba que as transformações sejam possíveis. Mostrar, por exemplo, que a prisão não existiu sempre, é permitir que se imagine, se não que ela possa não mais existir, pelo menos que se possa estabelecer uma outra economia da punição. A crítica radical serve para romper as falsas evidências, para sacudir a inércia dos hábitos. Contudo, Foucault não rejeita a noção de reforma, mas esta, para ele, não deve ser programada. Deve resultar de uma transformação real nas maneiras de pensar e das tensões, dos conflitos, das lutas que dela decorrem (ele toma como exemplo resistências aos "jogos de poder" em torno da loucura, da medicina, da doença, da penalidade, etc.) (Foucault, 1994c, p. 542-543). "Uma reforma, diz ele, nunca é senão o resultado de um processo no qual há conflito, afrontamento, luta, resistência” (Foucault, 1994a, p. 547) Ela é apenas o perfil provisório de uma nova relação de forças. Daí o fato de Foucault rejeitar qualquer acusação de reformismo:

"Nestas lutas, (...) não se trata absolutamente de reformismo, já que o reformismo tem a função de estabilizar um sistema de poder ao final de um certo número de mudanças, enquanto em todas estas lutas, se trata da desestabilização dos mecanismos de poder, de uma desestabilização sem fim"(Foucault, 1994, p. 547).

A crítica é, de início, no sentido kantiano, a análise das condições do exercício da razão. Foucault historiciza esta questão: como se constituiu a razão política ocidental? Que processos contingentes ocasionaram a formação da racionalidade moderna, ao mesmo tempo individualizante e totalizante? A crítica, em seguida - passagem da questão crítica para a da Aufklärung - é a definição do presente ao qual pertencemos. Ora, diz Foucault, não estamos mais na época das tecnologias disciplinares (mesmo que sempre haja disciplinas). Estamos - por quanto tempo? - na era de uma racionalidade dividida, fendida de certo modo por dentro: cada vez mais totalizante, mas incessantemente confrontada com o intotalizável (este é o paradoxo liberal). Daí a possibilidade de novas formas de luta. A crítica é igualmente, com efeito - é seu terceiro sentido - a experiência permanente da ultrapassagem. A libertação, não como horizonte de uma liberação definitiva, mas como ultrapassagem, que precisa sempre ser reencenada, das linhas de crise que atravessam um sistema (suas “fronteiras"), tal é, para Foucault, a atitude política que se deve tentar realizar. 
SENELLART, Michel. The criticism of governamental reason in Michel Foucault. Tempo Social; Rev. Sociol. USP, S. Paulo, 7(1-2): 1-14, october 1995.

ABSTRACT: The article examines modern criticism of governamental reason which is focused by Foucault under two main aspects. First he analyses the concept of critique based on his own interpretation of Kant's work, articulated with an "ontology of the present". Besides this, Foucault analyses the place ocuppied by liberalism in this critical procedure. Thus the article intends to show that Foucault's criticism escapes from the imputation of reformism.

UNITERIMS:

Foucault, critical attitude, governamental reason, power, liberalism.

\section{REFERÊNCIASBIBLIOGRÁFCAS}

Bentham, J. (1977) L'oeil du povoir. In: Belfondo.

. Le panoptique. Paris ,

Dreitzel, Horst. (1987) Justis Beitrag zur Politizlsierung des deutschen Aufklärung. In: Bodecker H. E. e Hermann U. (ed.). Aufklärung als Politisierung - Politisierung der Aufklärung. Hamburgo, Felix Meiner. p. 158-177.

Dreyfus, H. \& Rabinow, P. (1984) Michel Foucault. Un parcours philosophique. Paris, Gallimard.

Florence, Maurice. (1984) Foucault. Dictionnaire des Philosophes. Paris, D. Huisman, PUF.

. (1994) Foucault - 1984. In: Foucault, M. Dits et écrits. Vol. IV. Paris, Gallimard.

Foucault, Michel. (1966) Les mots et les choses. Paris, Gallimard.

. (1975) Surveiller et punir. Paris, Gallimard.

. (1979) Naissance la biopolitique. Cours. Inédito.

. (1984) L'usage des plaisirs, Paris, Gallimard.

. (1990) Qu'est-ce que la critique? In:

Conférence du 27 mai

1978. Bulletin de la Société Française de Philosophie 2, avril-juin. Armand Colin.

. (1994) Dits et écrits. Vol. III, 1976-1979. Paris, Gallimard.

. (1994a) Est-il donc important de penser? In: . Dits et écrits Vol. IV. 1980-1988. Paris, Gallimard.

. (1994b) La governementalité. In: . Dits et écrits. Vol. III. 1976-1979. Paris Gallimard.

. (1994c) La philosophie analytique de la politique (Tokyo, 1978). In: . Dits et écrits. Vol. III. 1976-1979. Paris, Gallimard.

. (1994d) Les mailles du pouvoir (1976). In: . Dits et écrits.

Vol. IV. 1980-1988. Paris, Gallimard. 
. (1994e) Omnes et singulatim: vers une critique de la raison politique. In: . Dits et écrits. Vol. IV. 1980-1988. Paris, Gallimard. . (1994f) Qu'est-ce que les Lumières? In: . Dits et écrits. Vol. IV. 1980-1988. Paris Gallimard. p. 562-578. . (1994g) Qu'est-ce que les Lumières? In: . Dits et écrits. Vol. IV. 1980-1988.Paris, Gallimard. p. 679-688.

. (1994h) Structuralisme et post-structuralisme. In:
écrits. Vol. IV. 1980-1986. Paris, Gallimard.

• (1994h) Structuralisme et post-structuralisme. Dits et

Justi, von. (1756) Grundsätze der Policey-wissenschaft. Trad. francesa Eléments généraux de police. Paris, s/e. 1769.

Habermas, J. (1986) Une flèche dans le coeur du temps présent. Critique, Paris, Édition de Minuit, $n^{\circ}$ 471-472, août-septembre. . (1988) Le discours philosophique de la modernité. Paris, Gallimard.

Han, Béatrice. (1995) Michel Foucault entre l'historique et le transcendental. Val-de-Marne. Tese de doutorado. Université de Paris XII.

Paine, Thomas. (1792) Droits de l'homme. $2^{\mathrm{a}}$ parte, tradução francesa. Paris, s/e.

Rosanvallon P. (1984) La crise de l'État-providence. Paris, Éd. du Seuil.

Schiera, Pierangelo. (1968) Il cameralismo e l'assolutismo tedesco. Milão, A. Giuffrè.

Senellart, Michel. (1993) Michel Foucault: 'gouvernementalité' et raison d'État. La pensée politique, 1, Paris, Gallimard/Le Seuil.

Smith, Adam. (1776) La richesse des nations. IV, 2. Garnier/Flammarion. Tomo 2. 